\title{
Protection from inflammatory disease in insulin resistance: the role of mannan-binding lectin
}

\author{
J. M. Fernández-Real • M. Straczkowski • J. Vendrell • \\ F. Soriguer • S. Pérez del Pulgar • L. Gallart • \\ A. López-Bermejo • I. Kowalska • M. Manco • \\ F. Cardona • M. M. García-Gil • G. Mingrone • \\ C. Richart • W. Ricart • A. Zorzano
}

Received: 13 March 2006 / Accepted: 30 May 2006 / Published online: 29 August 2006

(C) Springer-Verlag 2006

\begin{abstract}
Aims/hypothesis Decreased sensing of the innate immune system may lead to chronic activation of the inflammatory cascade. We hypothesised that mannan-binding lectin (MBL) deficiency may confer risk of obesity and insulin resistance.

Materials and methods We performed a cross-sectional study of MBL protein concentration $(n=434)$ and $M B L 2$
\end{abstract}

J. M. Fernández-Real $(\bowtie) \cdot$ S. Pérez del Pulgar •

A. López-Bermejo - M. M. García-Gil - W. Ricart

Section of Diabetes, Endocrinology and Nutrition,

University Hospital of Girona 'Dr Josep Trueta',

Carretera de França s/n,

17007 Girona, Spain

e-mail: uden.jmfernandezreal@htrueta.scs.es

M. Straczkowski • I. Kowalska

Department of Endocrinology, Diabetology and Internal

Medicine, Medical University of Bialystok,

Bialystok, Poland

J. Vendrell · S. Pérez del Pulgar $\cdot$ L. Gallart $\cdot$ C. Richart

Unit of Endocrinology and Nutrition,

University Hospital of Tarragona 'Joan XXIII',

Tarragona, Spain

F. Soriguer $\cdot$ F. Cardona

Department of Endocrinology and Nutrition,

University Hospital 'Carlos Haya',

Málaga, Spain

\section{S. Pérez del Pulgar $\cdot$ A. Zorzano}

Department of Molecular Biochemistry and Biology,

Faculty of Biology,

University of Barcelona and Scientific Park of Barcelona,

Barcelona, Spain

M. Manco $\cdot$ G. Mingrone

Department of Endocrinology, Catholic University of Rome,

Rome, Italy gene mutations (exon 1) $(n=759)$ in association with obesity, markers of inflammation and insulin action (euglycaemic clamp, $n=113$ ), and a longitudinal study of MBL protein before and after weight loss in obese patients $(n=10)$. We also studied the effects of MBL in vitro in muscle cells and circulating MBL-A (mouse equivalent of human MBL) in a mouse model.

Results Among 434 consecutive non-diabetic men, the ageadjusted serum MBL concentration was lower in obese subjects than in lean subjects (median: $959 \mu \mathrm{g} / \mathrm{ml}$ [interquartile range: $116.8-2,044 \mu \mathrm{g} / \mathrm{ml}]$ vs $1,365[467-2,513] \mu \mathrm{g} / \mathrm{ml}$; $p=0.01$ ) and was accompanied by increased serum inflammatory markers. Insulin action correlated significantly with serum MBL $(r=0.49, p<0.0001)$. Serum MBL concentration increased by a median of $110.2 \%$ after weight loss. The change in serum concentration of MBL was positively associated with the increase in insulin sensitivity $(r=0.713$, $p=0.021$ ). At least one $M B L 2$ gene mutation was present in $48.2 \%$ of obese vs $39.3 \%$ of non-obese subjects $(p=0.037)$. The plasma concentration of MBL-A was lower in insulinresistant obese $o b / o b$ mice, as was the glucose/insulin ratio. Incubation of rat soleus muscle with human MBL markedly increased fatty acid oxidation.

Conclusions/interpretation These findings suggest that MBL, previously thought only to be involved in inflammation and immune system function, affects metabolic pathways.

Keywords Cytokines · Inflammation ·

Innate immune system $\cdot$ Insulin resistance .

DNA polymorphism

$\begin{array}{ll}\text { Abbreviations } & \\ \text { FFM } & \text { fat-free mass } \\ \text { MBL } & \text { mannan-binding lectin }\end{array}$




$\begin{array}{ll}\text { MBL-A } & \begin{array}{l}\text { mouse equivalent of human mannan- } \\ \text { binding lectin }\end{array} \\ \text { sTNFR1 and } & \begin{array}{l}\text { soluble fractions of TNF- } \alpha \text { receptors } 1 \\ \text { and } 2\end{array}\end{array}$

\section{Introduction}

The prevalences of obesity and the metabolic syndrome have risen dramatically worldwide [1] and both pose a serious health hazard that contributes to the increased morbidity and mortality in Western societies. Obesity is frequently accompanied by related metabolic perturbations in which insulin resistance appears to be important. Although insulin resistance, by definition, describes impaired biological responsiveness to insulin, the term is frequently used to describe a defect in insulin-stimulated glucose uptake by muscle and adipocytes and/or a defect in the insulin-induced decrease in gluconeogenesis by the liver.

Impressive evidence has accumulated over the past decade that insulin resistance is linked to inflammatory pathways [2-6]. The origin of this inflammation is unknown. The immune system is constantly exposed to diverse bacterial products. The sensing arm of this immune system is efficient in buffering bacterial and environmental substances. Mannan- or mannose-binding lectin (MBL) is a liver-derived serum protein involved in innate immune defence. The ligands for MBL are mannose and $\mathrm{N}$-acetyl glucosamine oligosaccharides, expressed by a wide range of microorganisms. MBL may activate complement by means of the lectin pathway when interacting with MBLassociated serine proteases and can directly opsonise pathogens and enhance the activity of phagocytes by means of novel receptors [7, 8]. Interestingly, there is a correlation between increased concentrations of certain complement components (C3) and decreased insulin action [9]. Increased levels of $\mathrm{C} 3$ and other inflammatory markers in insulin resistance seem to result from chronic inflammation induced by 'excess' fat tissue, but it could be also the result of the relative inability to buffer the environmental inducers of inflammation. In this regard, decreased inherited ability to sense environmental substances would lead to increased exposure of cell immune systems to these products and a low-grade chronic inflammation.

MBL is an excellent model to test this hypothesis. MBL deficiency is the most frequent immunodeficiency in humans. It leads to an increased incidence of infections in subjects with MBL gene mutations [10]. Serum MBL concentrations vary widely from person to person because of three variant alleles $(\mathrm{B}, \mathrm{C}$ and $\mathrm{D}$, denoting the substitution of aspartic acid for glycine at codon 54, the substitution of glutamic acid for glycine at codon 57 , and the substitution of cysteine for arginine at codon 52, respectively) encoding the structural moiety of the functional MBL gene, MBL2, located on chromosome 10 in humans [11] (MBL2 is the functional gene; one expressed pseudogene [MBL1PI] also exists). The normal allele of $M B L 2$ is named $\mathrm{A}$ and the common designation for the variant alleles is $\mathrm{O}$. Each of the three variant alleles influences the stability of the final protein product, resulting in reduced serum levels and a dysfunctional MBL variant with a lower molecular weight than the normal protein [12-14].

We have recently reported that pregnant women bearing $M B L 2$ gene mutations had a greater risk of developing gestational diabetes and having heavier infants [15]. On the other hand, a high MBL level was also associated with a greatly decreased risk of myocardial infarction in diabetic or hypercholesterolaemic individuals in a recent report [16].

The associations of MBL with obesity and insulin action have not been investigated before. We hypothesised that MBL deficiency, by virtue of a relative inability to sense environmental products, could lead to a chronically activated inflammatory cascade, resulting in insulin resistance. We postulated that low circulating MBL might be associated with insulin resistance and obesity. To evaluate these possibilities, we studied in humans: (1) MBL protein concentration in subjects with different degrees of obesity; (2) MBL protein concentration in association with insulin action; (3) whether weight loss affects the circulating MBL concentration (a longitudinal study); and (4) MBL2 gene mutations in association with obesity. We also evaluated circulating MBL-A (mouse equivalent of human MBL) and the glucose/insulin ratio in a murine model of obesity and the possible in vitro metabolic action of MBL in rat soleus muscle.

\section{Subjects, materials and methods}

\section{Subjects}

Consecutive, unselected (except for glucose tolerance criteria) Caucasian subjects, participants in an ongoing epidemiological study of risk factors for cardiovascular disease, were included in the human study. Subjects were randomly recruited from a census and were invited to participate. These non-diabetic subjects were recruited at the Hospital of Girona (434 men) and Hospital Carlos Haya (Málaga, Spain) $(n=325)$. The participation rate was $71 \%$ at Girona [17] and $>90 \%$ at Málaga [18]. Subjects had a fasting plasma glucose concentration $<7.0 \mathrm{mmol} / 1$ and $2 \mathrm{~h}$ post-load plasma glucose $<11.1 \mathrm{mmol} / \mathrm{l}$ after a 75 -g oral glucose tolerance test according to the American Diabetes Association criteria. Inclusion criteria were (1) 
BMI $<40 \mathrm{~kg} / \mathrm{m}^{2}$, (2) absence of systemic disease, and (3) absence of infection within the previous month, as indicated in a clinical questionnaire [19]. None of the subjects was under medication or had evidence of metabolic disease other than obesity. All subjects gave written informed consent after the purpose of the study had been explained to them. The institutional review boards of the participating institutions approved the protocol.

\section{Study of insulin sensitivity}

The subjects were non-diabetic ( $n=113)$, aged $20-50$ years (anthropometric and biochemical characteristics are described in Table 1) and were recruited in Bialystok (Poland) following the same protocol and inclusion criteria as those detailed above. These subjects were actively recruited from patients hospitalised in the Department of Endocrinology, Diabetology and Internal Medicine, from patients from the outpatient clinic, and from medical staff and medical students. The institutional review board approved the study. Informed consent was obtained from all subjects participating in this study.

\section{Euglycaemic-hyperinsulinaemic clamp procedure}

Alcohol and caffeine were withheld for $12 \mathrm{~h}$ prior to the insulin sensitivity tests. After $12 \mathrm{~h}$ of fasting, insulin sensitivity was determined with the euglycaemic-hyperinsulinaemic clamp procedure $[20,21]$. Whole-body glucose uptake ( $\mathrm{M}$ value for insulin sensitivity in $\mu \mathrm{mol} \mathrm{kg}$ fat-free mass $[\mathrm{FFM}]^{-1} \mathrm{~min}^{-1}$ ) was determined during a primed constant infusion of insulin (at the rate of $6 \mathrm{pmol} \mathrm{min}^{-1} \mathrm{~kg}$ $\mathrm{FFM}^{-1}$ ). Whole-body peripheral glucose utilisation was calculated during the last 40-min period of the steady-state insulin infusion.

For these subjects from Poland the genetic and protein data for MBL were analysed at a single institution (Hospital of Girona, using the same methods as those detailed below) and were not included in the genetic analyses of association with obesity.

\section{Longitudinal study}

The study group consisted of an independent series of severely obese (BMI $>35 \mathrm{~kg} / \mathrm{m}^{2}$, FFM $71.2 \pm 9.31 \mathrm{~kg}$ ) subjects studied on two separate occasions: before and $\approx 2$ years after biliopancreatic diversion. These subjects were evaluated at the Catholic University of Rome, Italy. Their characteristics were not included in any of the analyses concerning $\mathrm{MBL}$ protein or $M B L 2$ gene mutations cited below. Detailed studies of body composition and insulin sensitivity (clamp procedure) were performed both before and after weight loss. None had

Table 1 Characteristics of the subjects according to MBL allele variants in exon 1 of the MBL gene

\begin{tabular}{|c|c|c|c|}
\hline & Subjects with no mutations $(n=75)$ & Subjects with at least one mutation $(n=38)$ & $p$ \\
\hline Sex (men/women) & $36 / 39$ & $14 / 24$ & 0.26 \\
\hline Age (years) & $30.62 \pm 8.22$ & $29.24 \pm 8.09$ & 0.36 \\
\hline BMI $\left(\mathrm{kg} / \mathrm{m}^{2}\right)$ & $26.72 \pm 4.95$ & $27.04 \pm 5.88$ & 0.74 \\
\hline Waist-to-hip ratio & $0.84 \pm 0.08$ & $0.83 \pm 0.07$ & 0.52 \\
\hline Percentage of body fat & $24.91 \pm 10.23$ & $26.72 \pm 12.65$ & 0.43 \\
\hline $\mathrm{HbA}_{1 \mathrm{c}}(\%)$ & $5.53 \pm 0.52$ & $5.72 \pm 0.74$ & 0.17 \\
\hline Fasting glucose $(\mathrm{mmol} / \mathrm{l})$ & $5.25 \pm 0.7$ & $5.26 \pm 0.84$ & 0.95 \\
\hline Postload glucose (mmol/l) & $5.89 \pm 2$ & $6.08 \pm 2.2$ & 0.68 \\
\hline Fasting insulin (pmol/l) & $87.15 \pm 59.69$ & $97.84 \pm 56.26$ & 0.33 \\
\hline Postload insulin (pmol/1) & $348.1 \pm 283$ & $456.2 \pm 274.5$ & 0.17 \\
\hline $\mathrm{M}\left(\mu \mathrm{mol} \mathrm{kg} \mathrm{FFM}{ }^{-1} \min ^{-1}\right)$ & $42.58 \pm 20.56$ & $31.49 \pm 13.90$ & 0.009 \\
\hline Total cholesterol (mmol/l) & $4.79 \pm 0.86$ & $5.28 \pm 1.40$ & 0.04 \\
\hline Triglycerides (mmol/l) & $1.32 \pm 0.82$ & $1.92 \pm 1.77$ & 0.029 \\
\hline HDL cholesterol $(\mathrm{mmol} / \mathrm{l})$ & $1.28 \pm 0.39$ & $1.24 \pm 0.27$ & 0.62 \\
\hline LDL cholesterol (mmol/1) & $2.97 \pm 0.79$ & $3.28 \pm 1.17$ & 0.14 \\
\hline $\mathrm{TNF}-\alpha(\mathrm{pg} / \mathrm{ml})$ & $0.53 \pm 0.57$ & $0.57 \pm 0.68$ & 0.82 \\
\hline sTNFR1 (ng/ml) & $2.22 \pm 0.52$ & $2.40 \pm 0.71$ & 0.29 \\
\hline sTNFR2 (ng/ml) & $4.57 \pm 1.14$ & $5.13 \pm 1.68$ & 0.16 \\
\hline Adiponectin (ng/ml) & $2.03 \pm 1.08$ & $1.59 \pm 0.78$ & 0.038 \\
\hline $\operatorname{MBL}(\mu \mathrm{g} / \mathrm{ml})^{\mathrm{a}}$ & $3418(726-4238)$ & $871(326-1181)$ & 0.000014 \\
\hline Log MBL & $7.68 \pm 1.14$ & $6.07 \pm 1.30$ & $<0.000001$ \\
\hline
\end{tabular}

$M$ Insulin sensitivity

${ }^{\mathrm{a}}$ Median and interquartile range 
impaired glucose tolerance, diabetes mellitus or any other endocrine or non-endocrine disease.

Genetic analyses

Genomic DNA was isolated from peripheral blood samples using a commercially available extraction kit (QIAamp DNA blood; Qiagen, Venlo, the Netherlands). In exon 1 of the MBL2 gene, the presence of three single-base substitutions was investigated - at codon 54 (the B allele), codon 57 (the $\mathrm{C}$ allele), and codon 52 (the D allele)-by PCR using the intronic primers MBL-1F GAGGG CATGCTCGGTAAATA and MBL-1R CAGG CAGTTTCCTCTGGAAG. PCR conditions were initial denaturation at $94^{\circ} \mathrm{C}$ for $5 \mathrm{~min}$ followed by 35 cycles of denaturation at $94^{\circ} \mathrm{C}$ for $1 \mathrm{~min}$, annealing at $60^{\circ} \mathrm{C}$ for $1 \mathrm{~min}$ and extension at $72^{\circ} \mathrm{C}$ for $1 \mathrm{~min}$ and a final extension at $72^{\circ} \mathrm{C}$ for $7 \mathrm{~min}$. PCR products were purified using GFX PCR DNA and gel purification kit (Amersham Biosciences, Uppsala, Sweden) and automatically sequenced with the fluorescent BigDye Terminator v3.1 (PE Applied Biosystems, Foster City, CA, USA) and the automatic sequencer ABI Prism 310 (Applied Biosystems).

Analytical methods

Plasma glucose was measured immediately using the glucose analyser YSI 2300 STAT Plus (YSI, Yellow Springs, OH, USA). Total serum cholesterol was measured using the reaction of cholesterol esterase/cholesterol oxidase/peroxidase. HDL cholesterol was quantified after precipitation with polyethylene glycol at room temperature. Total serum triglycerides were measured through the reaction of glycerol phosphate oxidase and peroxidase. $\mathrm{HbA}_{1 \mathrm{c}}$ was measured with a high-performance liquid chromatography method (Bio-Rad, Munich, Germany); the recommended normal range of the assay was 4.1$6.5 \%$. Plasma TNF- $\alpha$ concentrations were measured with the Immunoassay Kit (BioSource International, Camarillo, CA, USA) with the minimum detectable concentration $1.7 \mathrm{pg} / \mathrm{ml}$ and intra- and interassay $\mathrm{CVs}$ of $<5.2$ and $<8.5 \%$, respectively. The plasma-soluble fractions of TNF- $\alpha$ receptors (sTNFR1 and sTNFR2) were determined with EASIA kits. The intra- and interassay CVs for the two receptors were $<6.5$ and $<9 \%$, respectively.

Plasma levels of MBL in humans were determined using commercially available MBL ELISA kits (AntibodyShop, Copenhagen, Denmark). Intra- and interassay coefficients of variation were below $8 \%$.

A radioimmunoassay (Linco Research, St Charles, MO, USA) was used to measure plasma adiponectin concentrations. The intra- and interassay coefficients of variation were $<5 \%$.
Animal studies

\section{In vitro muscle incubation}

Male Wistar Hanover rats (60-80 g) were purchased from Harlan Iberica, Sant Feliu de Codines, Barcelona, Spain. They were housed in a controlled environment on a $12 \mathrm{~h}$ light/12 $\mathrm{h}$ dark cycle and fed a standard chow diet. Water and food were available ad libitum. On the experimental day, rats were anaesthetised with pentobarbital sodium (60 $\mathrm{mg} / \mathrm{kg}$ i.p.) and the soleus muscle was carefully dissected and placed in $1 \mathrm{ml}$ of cold Krebs-Henseleit HEPES buffer ( $\mathrm{pH}$ 7.4), supplemented with $5 \mathrm{mmol} / \mathrm{l}$ glucose, until all the muscles had been collected. Soleus muscles $(30 \pm 1 \mathrm{mg})$ were preincubated for $20 \mathrm{~min}$ at $37^{\circ} \mathrm{C}$ in $2 \mathrm{ml}$ of Krebs-Henseleit HEPES buffer containing $2 \%$ bovine serum albumin (fatty acid free-BSA; Sigma, $\mathrm{St}$ Louis, MO, USA) and $5 \mathrm{~mol} / 1$ glucose (incubation medium). The media were gassed continuously with $95 \%$ $\mathrm{O}_{2}, 5 \% \mathrm{CO}_{2}$. The medium was then removed and the muscles were incubated for $90 \mathrm{~min}$ at $37^{\circ} \mathrm{C}$ in $1 \mathrm{ml}$ of fresh medium with the following additions: none (baseline), insulin (100 nmol/l), MBL (50 $\mathrm{gg} / \mathrm{ml}$ human MBL; US Biologicals, Swampscott, MA, USA) or insulin plus MBL.

\section{Glucose and fatty acid oxidation}

For glucose oxidation studies, $0.11 \mathrm{MBq} / \mathrm{ml} \mathrm{D}-[\mathrm{U}]-{ }^{14} \mathrm{C}$ glucose (Amersham Biosciences) was added to the incubation medium. For fatty acid oxidation studies, the incubation medium contained $0.11 \mathrm{MBq} / \mathrm{ml}[1]-{ }^{14} \mathrm{C}$-palmitic acid (Amersham Biosciences), $100 \mu \mathrm{mol} / 1$ palmitic acid (Sigma), $50 \mu \mathrm{mol} / 1 \mathrm{NaOH}, 0.5 \% \mathrm{EtOH}$ and $0.8 \mathrm{mg} / \mathrm{ml} \mathrm{BSA}$. The muscles were incubated for $60 \mathrm{~min}$ at $37^{\circ} \mathrm{C}$. Gassing was terminated after the initial $15 \mathrm{~min}$. The test tubes were hermetically closed with turnover flange rubber stoppers (Saint-Gobain Verneret, Charny, France) with a centre well that contained a piece of filter paper secured with a staple. At the end of the incubation, the medium was acidified with $0.3 \mathrm{ml}$ of $0.5-\mathrm{N} \mathrm{H}_{2} \mathrm{SO}_{4}$ and the filter paper was saturated with $200 \mu \mathrm{l}$ of benzetonium hydroxide (Hyamine; Sigma) to trap gaseous ${ }^{14} \mathrm{CO}_{2}$ liberated after the acidification. The vials were shaken at $37^{\circ} \mathrm{C}$ for $60 \mathrm{~min}$, and the filter papers were removed and transferred to vials for liquid scintillation counting.

\section{Ob/ob mice}

Twelve-week-old lean and obese $o b / o b$ male mice were obtained from The Jackson Laboratory (Bar Harbor, ME, USA). Blood was obtained from overnight-fasted mice and glucose was measured with a glucometer (Menarini, Badalona, Barcelona, Spain) and plasma insulin was 
measured by ELISA (Ultrasensitive Mouse Insulin ELISA; Mercodia, Uppsala, Sweden).

Circulating MBL-A in these mice was measured using ELISA test kits for mouse MBL-A (Hycult Biotechnology, Madrid, Spain). Intra- and interassay coefficients of variation were below $10 \%$.

\section{Statistical analyses}

Before statistical analysis, normal distribution and homogeneity of the variances were evaluated using Levene's test and then variables were log-transformed if necessary. These parameters were analysed on a log scale and tested for significance on that scale. The antilog-transformed values of the means are reported in the tables. Relations between variables were tested using Pearson's test and stepwise multiple linear regression analysis. Differences between groups were assessed with the $\chi^{2}$ test, one-way ANOVA followed by Dunn or Bonferroni correction as appropriate, and unpaired or paired $t$-tests for comparisons of quantitative variables. To study the covariance of MBL, sTNFR1 and IL-6, we used multivariate analysis of variance after taking into account the effect of age. All tests were twosided and the level of significance was set at 0.05 .

To determine the importances of the different MBL variant alleles, we assessed the effect of the number of MBL2 gene mutations on disease (obesity) versus nondisease status. Compound heterozygotes were defined as individuals with any combination of the three $M B L 2$ gene mutations. We compared each of the three single-nucleotide polymorphisms individually and additively against dependent variables (age-adjusted obese status). The mutations were tested as dominant [13]. None of the subjects was related to each other. In the comparison of the prevalence of at least one mutation of exon 1 according to obese status, the statistical power to detect statistical differences was $56 \%$, assuming an alpha risk of $5 \%$ in a two-sided contrast. The statistical power for the uncommon mutations in codon 52 (in all subjects) and 57 (in women) was 58 and $71 \%$, respectively. All the analyses were performed using SPSS (version 11.0).

\section{Results}

MBL protein in subjects with different degrees of obesity

Among 434 consecutive non-diabetic men who were recruited at a single institution (Hospital of Girona), ageadjusted serum MBL was significantly lower in obese subjects than in lean subjects (median: $959 \mu \mathrm{g} / \mathrm{ml}$ [interquartile range: $116.8-2,044]$ vs 1,365 [467-2,513] $\mu \mathrm{g} / \mathrm{ml}$, $p=0.01$ ) (Fig. 1a). This finding was accompanied by increased serum C-reactive protein (CRP), IL-6 and sTNFR1 in obese subjects (Fig. 1b-d). Each change in BMI category (Garrow classification) led to concomitant variations in CRP, IL-6 and sTNFR1 along with MBL in three different statistical models ( $p$ values between 0.035 and 0.047 ).

MBL protein in association with insulin action

Insulin action (clamp value) correlated significantly with serum MBL protein concentration $(r=0.49, p<0.0001$; $n=113$ ) (Fig. 2). Carriers of at least one of the three mutations of exon 1 had significantly decreased insulin action and a lower circulating adiponectin concentration (Table 1). The association between insulin sensitivity and circulating MBL persisted after adjustment for sex, age, BMI (adjusted beta for $\mathrm{BMI}=0.30, p=0.000053$ ) and waistto-hip ratio (adjusted beta $=0.29, p=0.001$ ). The slope of the association between serum MBL concentration and insulin sensitivity was similar in carriers and non-carriers of MBL
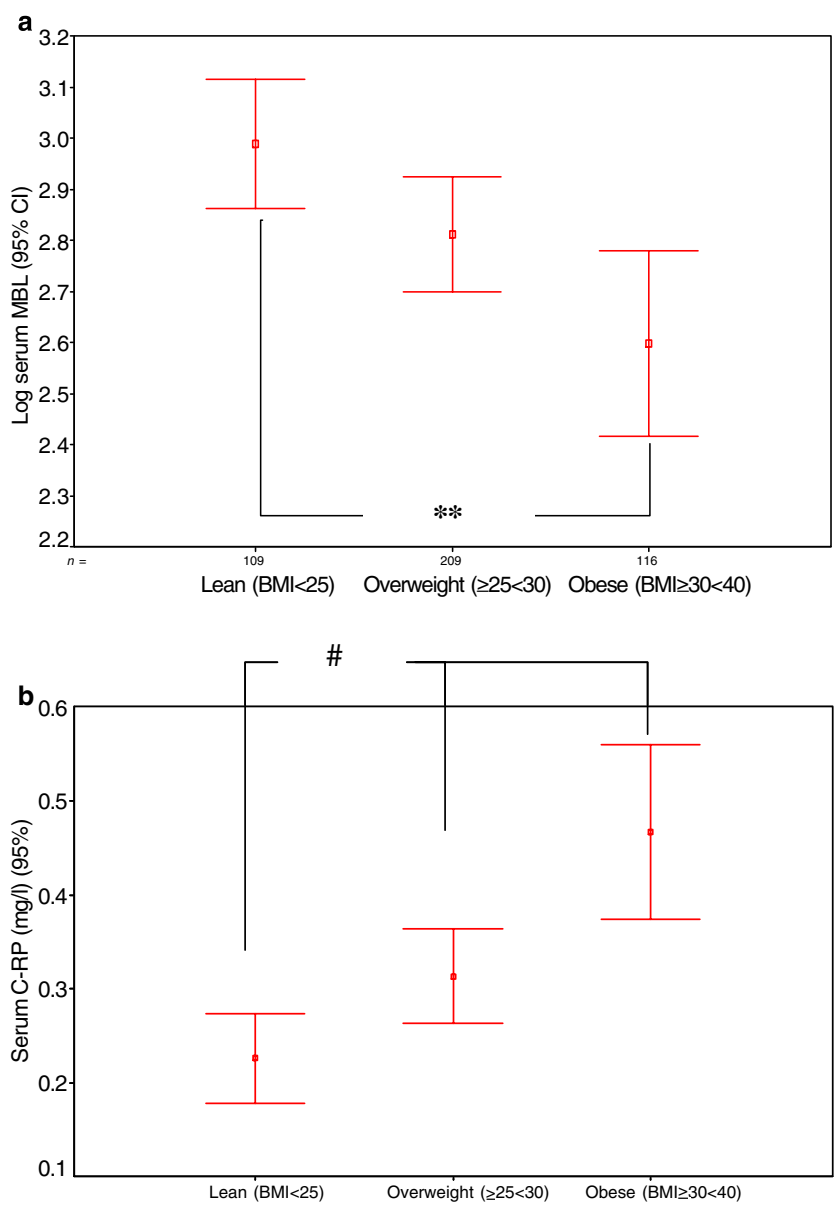

Fig. 1 Mean and $95 \% \mathrm{CI}$ of serum MBL (a), C-reactive protein (C-RP) (b), IL-6 (c) and sTNFR1 (d) concentrations across BMI categories according to the Garrow classification (lean subjects, BMI $<25 \mathrm{~kg} / \mathrm{m}^{2}$; overweight subjects, $\mathrm{BMI} \geq 25$ and $<30$; obese subjects, $\mathrm{BMI} \geq 30$ and $<40 \mathrm{~kg} / \mathrm{m}^{2}$ ). ** $p=0.01 ; \# p<0.0001 ; \dagger p=0.0043$ 
Fig. 1 (continued)
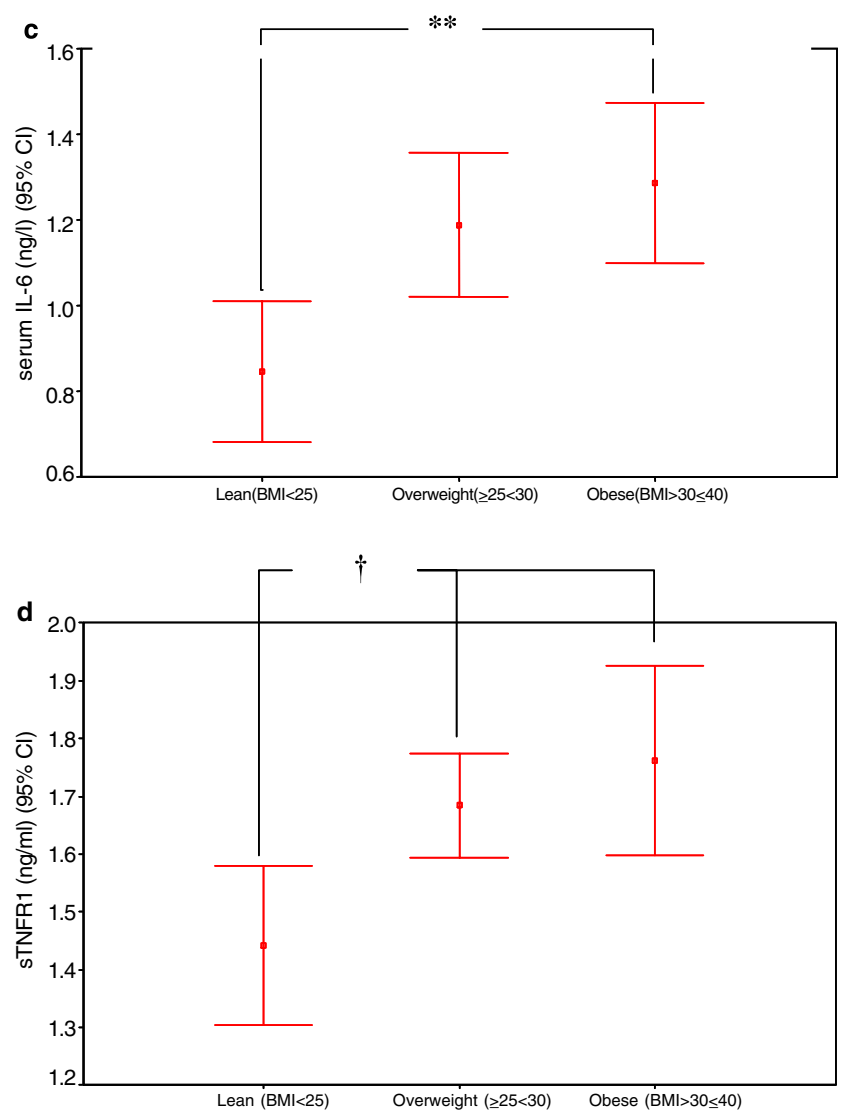

gene mutations (two tailed $p$-value for the difference between correlation coefficients, 0.64).

Longitudinal study: weight loss leads to increased circulating MBL

In these subjects (three men and seven women, aged $43.8 \pm$ 6.4 years), who were evaluated in an independent study, BMI decreased from $43.2 \pm 5.4$ to $31.2 \pm 4.3 \mathrm{~kg} / \mathrm{m}^{2}$ $(p<0.0001)$. Insulin sensitivity (corrected M clamp value) increased after weight loss (from $2.27 \pm 0.67$ to $6.72 \pm$ $\left.0.98 \mathrm{mg} \mathrm{kg}^{-1} \min ^{-1}, p<0.0001\right)$. As expected, the change in insulin sensitivity correlated inversely with the change in body weight $(r=-0.734, p=0.016$; Fig. $3 a)$; i.e. the greater the weight loss, the greater the insulin sensitivity. Interestingly, the change in serum MBL concentration was positively associated with the increase in insulin sensitivity ( $r=0.713, p=0.021$; Fig. $3 \mathrm{~b}$ ) but not with the change in BMI ( $r=-0.496, p=0.14$; Fig. $3 \mathrm{c}$, in which the apparent association was entirely due to two outliers). However, after controlling for the change in $\mathrm{BMI}$, the relationship between the change in MBL and the change in insulin sensitivity was no longer significant $(r=0.42, p=0.26)$. Mean log serum $\mathrm{MBL}$ increased from $3.16 \pm 0.33$ to $3.43 \pm 0.30$ (mean

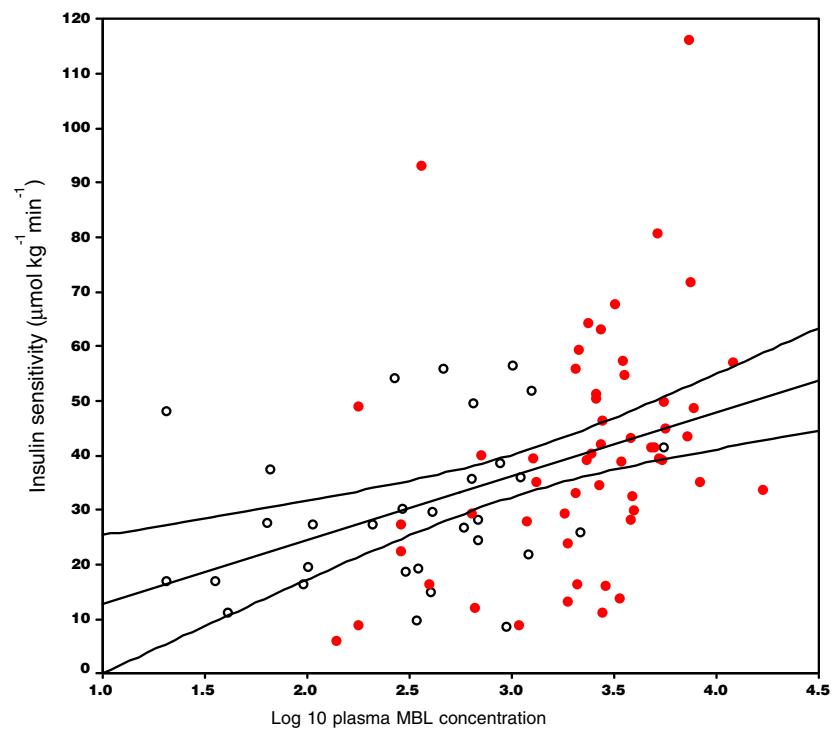

Fig. 2 Linear correlation analysis of the association between circulating MBL protein and insulin sensitivity (derived from data of euglycaemic-hyperinsulinaemic clamp). The mutated allele (open circles) refers to the presence of any of three single-base substitutions at codon 54 (B allele), codon 57 (C allele) and codon 52 (D allele). Red circles, wild-type; curves, total population. The genetic and protein results of these subjects were not included in the genetic analyses of the association with obesity. $r=0.49 ; p<0.0001 ; n=113$

difference $0.27,95 \%$ CI: 0.13-0.40). Serum MBL increased by a median of $110.2 \%$ (interquartile range: $33.2-143 \%$ ) after weight loss.

$M B L 2$ gene variants in association with obesity

MBL2 gene polymorphism of exon 1 was analysed in 759 subjects. These subjects included those in whom MBL protein was analysed $(n=434)$. The frequencies of the different mutations were similar and were in HardyWeinberg equilibrium in the subjects recruited at both institutions (Hospital of Girona and Hospital of Málaga), and these results were therefore pooled for further analysis. The frequencies of the MBL B, C and D mutations were 23.4, 3.7 and $9.2 \%$ respectively, similar to those found in other Caucasian populations [12-14]. The serum concentration of MBL protein was markedly different among these groups: the median value was $2,589 \pm \mu \mathrm{g} / \mathrm{ml}(95 \% \mathrm{CI}$ : 2,334-2,844 $\mu \mathrm{g} / \mathrm{ml}$ ) in wild-type (A allele); $771.8 \mu \mathrm{g} / \mathrm{ml}$ (95\% CI: 602.4-941.2) in subjects heterozygous for only one mutation (any of the three of exon 1); $144.9 \mu \mathrm{g} / \mathrm{ml}$ (95\% CI: 17.5-272.3) in subjects homozygous for one mutation; and $25 \mu \mathrm{g} / \mathrm{ml}$ (95\% CI: 10.9-39.2) in subjects who were compound heterozygotes (heterozygous for at least two different mutations) $(p<0.00001)$.

At least one mutated allele was present in $48.2 \%$ of obese and in $39.3 \%$ of non-obese subjects $(p=0.037)$, and the R52C mutation (D allele) was present in $16.9 \%$ of 

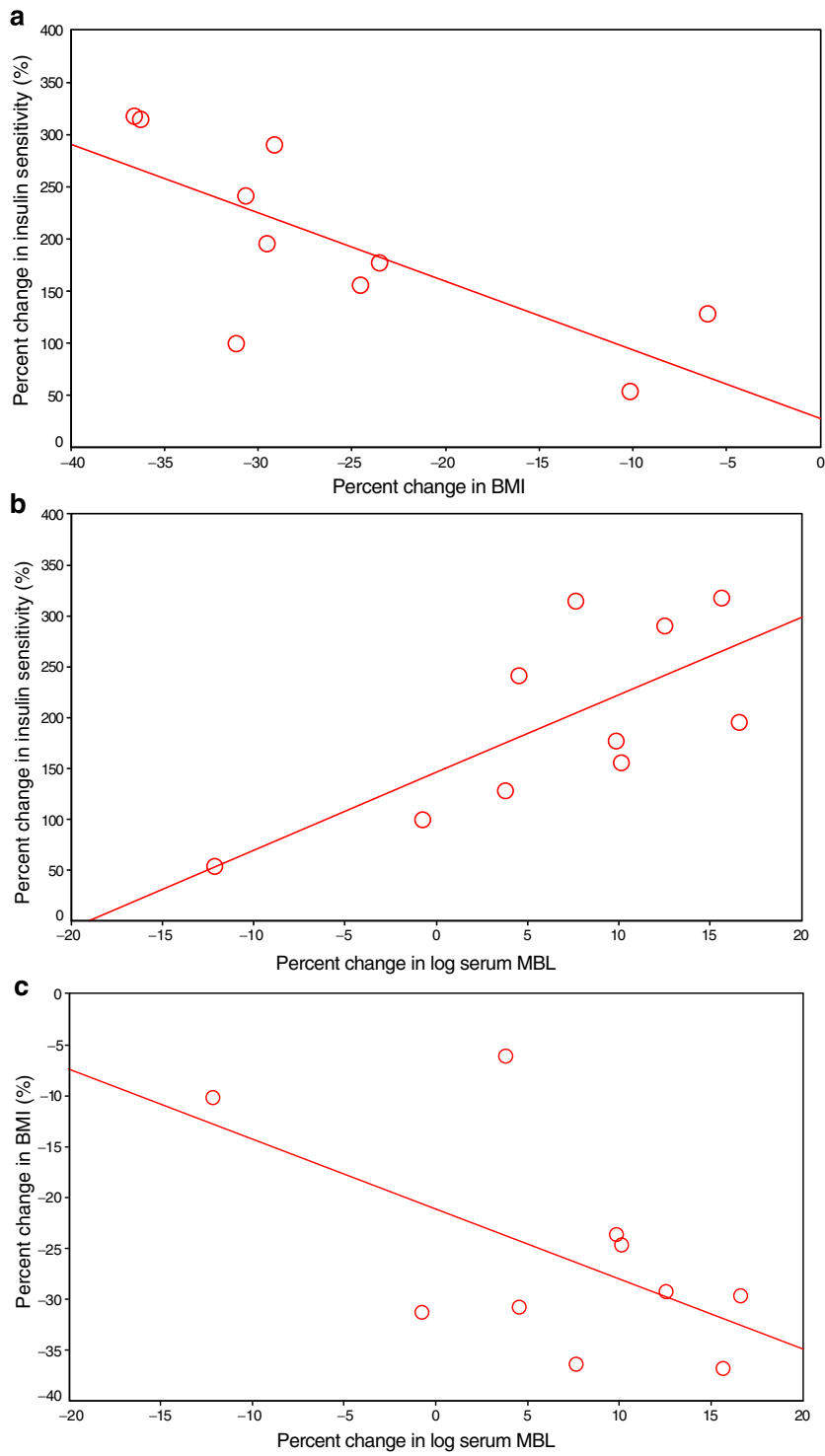

Fig. 3 Percentage change in insulin sensitivity in relation to a percentage change in BMI and $\mathbf{b}$ percentage change in serum MBL concentration. c Percentage change in BMI in relation to percentage change in serum MBL concentration

obese and in $10.7 \%$ of non-obese subjects $(p=0.024)$ (Table 2). In men, the R52C mutation (D allele) was present in $19.3 \%$ of obese and in $11.3 \%$ of non-obese men $(p=0.04)$. In women, the rare G57E mutation (C allele) was present in $7.7 \%$ of obese and $1.8 \%$ of non-obese women $(p=0.022)$.

MBL shows metabolic effects in rat skeletal muscle

On the basis of previous observations, we tested whether animal models characterised by insulin resistance were also linked to lower levels of circulating MBL. To this end, the plasma glucose/insulin ratio and MBL-A were measured in lean and obese $o b / o b$ mice. In keeping with insulin
Table 2 Age-adjusted prevalence of MBL allele variants in exon 1 of the $M B L 2$ gene according to obesity status

\begin{tabular}{llll}
\hline Mutation & $\begin{array}{l}\text { Obese } \\
(n=195)\end{array}$ & $\begin{array}{l}\text { Non-obese } \\
(n=564)\end{array}$ & $\begin{array}{l}p \\
-\end{array}$ \\
\hline R52C & $16.9 \%$ & $10.7 \%$ & 0.024 \\
G54D & $28.4 \%$ & $28.4 \%$ & 0.99 \\
G57E & $4.2 \%$ & $3.2 \%$ & 0.48 \\
Any mutation & $48.2 \%$ & $39.3 \%$ & 0.037 \\
\hline
\end{tabular}

resistance, obese $o b / o b$ mice showed a reduced glucose/ insulin ratio $(9.9 \pm 5$ and $69.6 \pm 25.4$ in $o b / o b[n=9]$ and lean $[n=9]$ mice respectively, $p<0.0001)$ and, under these conditions, plasma MBL-A was markedly reduced $(20 \pm 4$ and $26 \pm 3.7 \mathrm{ng} / 1$ in $o b / o b$ and lean mice, respectively; $p<0.001$ ) (Fig. 4a).

Next, we studied whether MBL could display direct metabolic effects in skeletal muscle that could explain the correlation between insulin sensitivity and circulating MBL concentrations. To this end, rat soleus muscles were incubated for $60 \mathrm{~min}$ with insulin $(100 \mathrm{nmol} / \mathrm{l})$, MBL $(50 \mu \mathrm{g} / \mathrm{ml})$ or MBL + insulin, and palmitate and glucose oxidations were subsequently measured. Incubation of rat soleus muscle with human MBL markedly increased fatty acid oxidation ( $4.9 \pm 0.7$ vs $2.5 \pm 0.5 \mathrm{nmol}$ palmitate per g wet weight per $\mathrm{h}$ in the MBL and control groups respectively; $p=0.016$ ) (Fig. 4b). Under these conditions, glucose oxidation was not modified by exposure to MBL (Fig. 4c).

\section{Discussion}

The presence of MBL deficiency in more than one-third of the human population makes it the most frequent immunodeficiency [12-14]. MBL deficiency has been previously reported to be associated with an increased incidence of infections [22, 23]. We found that decreased circulating MBL was associated with obesity and insulin resistance. This result is based on the following principal findings. (1) Circulating MBL was significantly lower among obese subjects. Overweight subjects had serum MBL concentrations intermediate between those of lean and obese subjects (Fig. 1a). (2) MBL2 gene variants were more frequently present in obese than in lean subjects. (3) Serum MBL was associated with insulin action. Subjects with MBL2 gene mutations, who were comparable in body fatness to subjects without such mutations, showed significantly decreased insulin action. (4) Circulating MBL increased after weight loss with improved insulin action in patients with morbid obesity. (5) Animal and in vitro data suggested that MBL may show metabolic actions. 

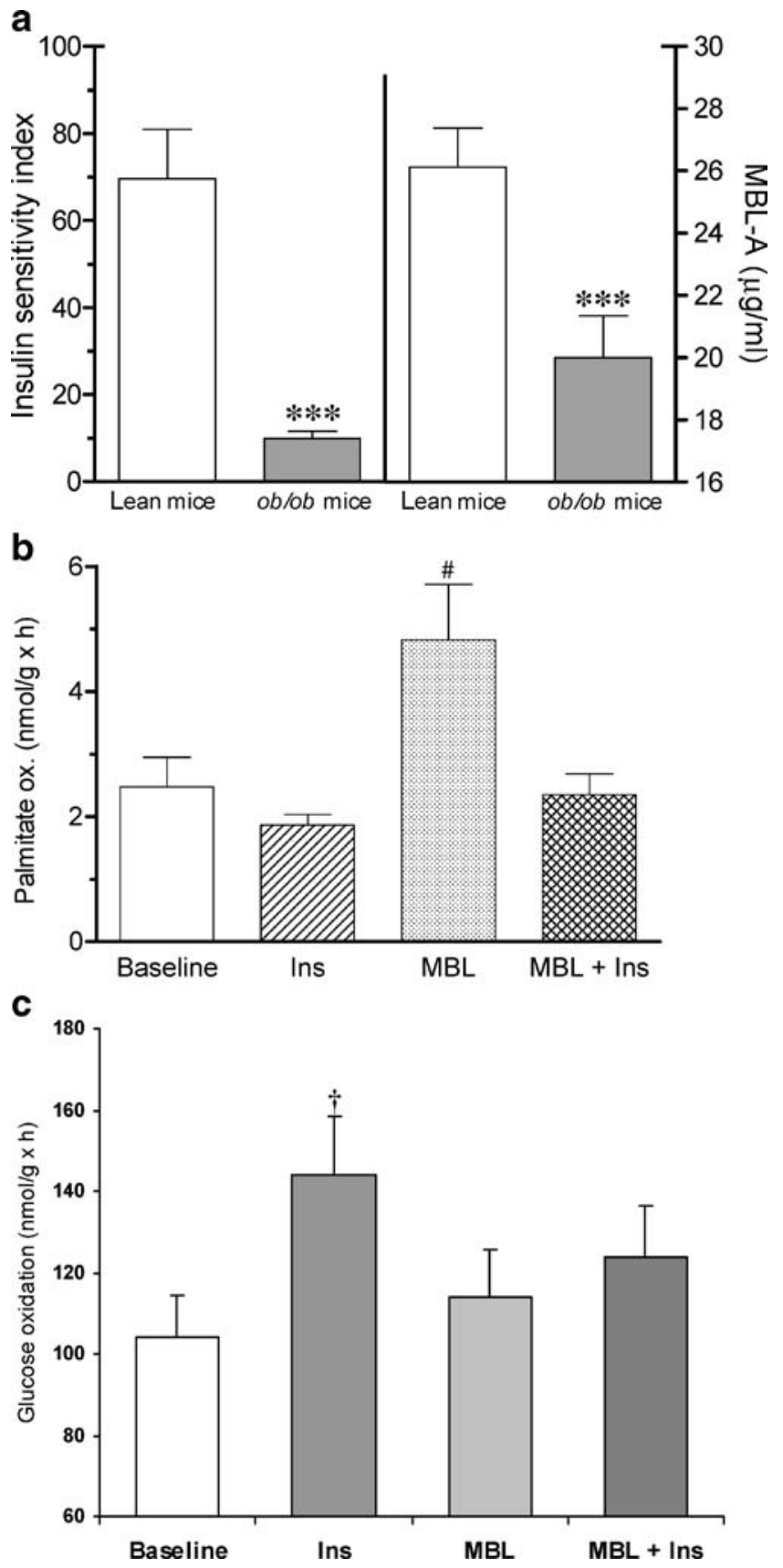

Fig. 4 a Insulin sensitivity index (glucose/insulin ratio) and plasma MBL-A concentration in $o b / o b$ and lean mice (nine in each group). $* * * p<0.001$. b In vitro fatty acid oxidation in isolated soleus muscles of fed rats incubated with insulin (Ins) $(100 \mathrm{nmol} / \mathrm{l})$, MBL $(50 \mu \mathrm{g} / \mathrm{ml})$ or $\mathrm{MBL}+$ Ins. For glucose oxidation studies, $0.11 \mathrm{MBq} / \mathrm{ml} \mathrm{D}$ - $[\mathrm{U}]-{ }^{14} \mathrm{C}$-glucose was added to the incubation medium. For fatty acid oxidation studies, the incubation medium contained $0.11 \mathrm{MBq} / \mathrm{ml}[1]-{ }^{14} \mathrm{C}$-palmitic acid, $100 \mu \mathrm{mol} / 1$ palmitic acid, $50 \mu \mathrm{mol} / 1 \mathrm{NaOH}, 0.5 \% \mathrm{EtOH}$ and $0.8-\mathrm{mg} / \mathrm{ml}$ BSA. The muscles were incubated for $60 \mathrm{~min}$ at $37^{\circ} \mathrm{C}$. Results are expressed as nmol (palmitate or glucose) g wet weight ${ }^{-1} \mathrm{~h}^{-1}$. Values represent mean \pm SEM for three or four muscles from each group. \# $p=0.016 \mathrm{vs}$ baseline, vs insulin-treated and vs insulin + MBL-treated muscles. c In vitro glucose oxidation in the same experiment. $\dagger p=0.030$ vs baseline
We found increased circulating markers of inflammation in obese subjects in association with decreased MBL concentrations. It is tempting to suggest that subjects with decreased MBL concentrations are more likely to develop repeated, chronic or persistent infections, resulting in lowgrade chronic inflammation, and ensuing insulin resistance or obesity. However, this is a cross-sectional observation and we cannot infer causality. It is equally plausible that chronic low grade inflammation may result in decreased serum MBL concentration.

The circulating MBL concentration was also positively associated with insulin action. This relationship mirrors the direct association between adiponectin and insulin action. In fact, adiponectin and MBL were also positively associated. As with obesity, MBL might promote metabolic effects, resulting in increased insulin action, but the reverse cannot be excluded: enhanced insulin action may result in increased MBL synthesis. In fact, intensive insulin therapy not only reduced the risk of severe infections and lethality but also overruled the increased vulnerability associated with low MBL levels in critically ill patients [24].

Given these difficulties in inferring cause and consequence, we also evaluated MBL2 gene mutations. We hypothesised that decreased MBL concentrations in individuals with MBL gene mutations might lead to insulin resistance through an enhanced inflammatory cascade. We found that this was the case in a relatively small sample: insulin action (clamp value) correlated significantly with serum MBL protein concentration $(r=0.49, p<0.0001$, $n=113$ ) (Fig. 2). This association persisted after adjustment for sex, age, BMI and waist-to-hip ratio. Carriers of at least one of the three mutations of exon 1 had significantly decreased insulin action and a lower circulating adiponectin concentration (Table 1).

Obese subjects showed an increased prevalence of at least one mutation of exon 1 (Table 2). However, the sample evaluated by us was relatively small and this result should be confirmed in other larger studies.

We observed that substantial weight loss over a 2-year period led to a median twofold increase in circulating MBL. Within-person variation in MBL concentration is fairly small, even in patients with chronic inflammatory diseases [22], but the concentration can temporarily increase up to threefold during acute-phase responses [7, 23]. Interestingly, the change in serum MBL concentration was positively associated with the increase in insulin sensitivity but not with the change in BMI $(r=-0.496, p=0.14)$. However, the constrained power in the longitudinal analysis of only ten subjects should be recognised, so we cannot exclude the possibility of a significant association with the change in BMI. In fact, after controlling for the change in BMI, the relationship between the change in MBL and the change in insulin sensitivity was no longer significant. 
The animal and in vitro data are also concordant with a possible metabolic effect of MBL. Circulating MBL-A, the murine equivalent of human MBL, was significantly lower in a murine model of obesity, $o b / o b$ mice, and was accompanied by a decreased glucose/insulin ratio as an expression of insulin resistance. In addition, treatment of rat soleus muscles with human MBL led to direct metabolic effects that might explain the correlation between insulin sensitivity and circulating MBL concentrations. Similarly to the effects of adiponectin, MBL stimulated fatty acid oxidation but not glucose oxidation in skeletal muscle [25]. In fact, human MBL shows some identity (14\%) to adiponectin, and both proteins have a similar structure with collagen-like and globular domains [26].

MBL is also able to enhance phagocytosis [27] and to reduce the release of TNF- $\alpha$, IL- 1 and IL-6 from monocytes [28], actions that, by decreasing inflammatory activity, may be linked to insulin action.

These observations seem to contradict recent articles describing increased MBL concentrations in patients with type 1 diabetes with microvascular complications [29-33]. However, MBL plays a dual role in modifying inflammatory responses to injury [34]. Mice that lack MBL, and hence are devoid of MBL-dependent lectin pathway activation but have fully active alternative and classical complement pathways, are protected from cardiac reperfusion injury with resulting preservation of cardiac function [35]. In fact, variant MBL alleles that cause dominant low-serum concentrations have high frequencies in all populations studied; therefore, low MBL concentrations may confer selective advantages on individuals carrying the variant alleles [34]. The changing environment may have determined that these 'selected' individuals are now more prone to obesity and insulin resistance [36]. On the other hand, MBL may also favour autoimmune processes [34]. In addition, the serum levels of IgG anti-MBL positively correlated with the MBL levels in autoimmune disease [37], which adds further complexity. As with so many factors in our physiology, 'the best is the middle': not too low, not too much.

In summary, the findings of the present study suggest that MBL, previously thought to be involved only in inflammation and immune system function, affects metabolic pathways and possibly influences the development of insulin resistance and obesity. It is hypothesised that, in subjects with MBL gene mutations, treatment with MBL might raise its concentration above a certain threshold of functional deficiency and protect them from developing obesity.

Acknowledgements This work was supported by research grants from the Spanish Ministry of Science and Technology (SAF2002-02125 and BFU 2004 -03654) and the Carlos III Institute of Health (RCMN C03/08, RGDM G03/212, RGTO G03/028). A. López-Bermejo is a research investigator of the Fund for Scientific Research 'Ramon y Cajal' (Ministry of Education and Science, Spain).

\section{References}

1. Ford ES, Giles WH, Mokdad AH (2004) Increasing prevalence of the metabolic syndrome among U.S. Adults. Diabetes Care 27:2444-2449

2. Ridker PM, Buring JE, Cook NR, Rifai N (2003) C-reactive protein, the metabolic syndrome, and risk of incident cardiovascular events: an 8-year follow-up of 14,719 initially healthy American women. Circulation 107:391-397

3. Festa A, D'Agostino R Jr, Howard G, Mykkanen L, Tracy RP, Haffner SM (2000) Chronic subclinical inflammation as part of the insulin resistance syndrome: the Insulin Resistance Atherosclerosis Study (IRAS). Circulation 102:42-47

4. Engström G, Hedblad B, Stavenow L, Lind P, Janzon L, Lindgärde F (2003) Inflammation-sensitive plasma proteins are associated with future weight gain. Diabetes 52:2097-2101

5. Schmidt MI, Duncan BB, Sharrett AR et al (1999) Markers of inflammation and prediction of diabetes mellitus in adults (Atherosclerosis Risk in Communities study): a cohort study. Lancet 353:1649-1652

6. Fernández-Real JM, Ricart W (2003) Insulin resistance and chronic cardiovascular inflammatory syndrome. Endocr Rev 24:278-301

7. Petersen SV, Thiel S, Jensenius JC (2001) The mannan-binding lectin pathway of complement activation: biology and disease association. Mol Immunol 38:133-149

8. Saevarsdottir S, Vikingsdottir, T, Valdimarsson H (2004) The potential role of mannan-binding lectin in the clearance of self-components including immune complexes. Scand J Immunol 60:23-29

9. Weyer C, Tataranni PA, Pratley RE (2000) Insulin action and insulinemia are closely related to the fasting complement $\mathrm{C} 3$, but not acylation stimulating protein concentration. Diabetes Care 23:779-785

10. Koch A, Melbye M, Sorensen P et al (2001) Acute respiratory tract infections and mannose-binding lectin insufficiency during early childhood. JAMA 285:1316-1321

11. Taylor ME, Brickell PM, Craig RK, Summerfield JA (1989) Structure and evolutionary origin of the gene encoding a human serum mannose-binding protein. Biochem J 262:763-771

12. Gadjeva M, Takahashi K, Thiel S (2004) Mannan-binding lectin - a soluble pattern recognition molecule. Mol Immunol 41:113-121

13. Garred P, Larsen F, Madsen HO, Koch C (2003) Mannose-binding lectin deficiency - revisited. Mol Immunol 40:73-84

14. Steffensen R, Thiel S, Varming K, Jersild C, Jensenius JC (2000) Detection of structural gene mutations and promoter polymorphisms in the mannan-binding lectin (MBL) gene by polymerase chain reaction with sequence-specific primers. J Immunol Methods 241:33-42

15. Megia A, Gallart L, Fernández-Real JM et al (2004) Mannosebinding lectin gene polymorphism are associated with gestational diabetes mellitus. J Clin Endocrinol Metab 89:5081-5087

16. Saevarsdottir S, Oskarsson OO, Aspelund T et al (2005) Mannan binding lectin as an adjunct to risk assessment for myocardial infarction in individuals with enhanced risk. J Exp Med 201:117-125

17. Fernandez-Real JM, Lopez-Bermejo A, Castro A et al (2005) Opposite relationship between circulating soluble CD14 concentration and endothelial function in diabetic and nondiabetic subjects. Thromb Haemost 94:615-619

18. Soriguer F, Rojo-Martinez G, Dobarganes MC et al (2003) Hypertension is related to the degradation of dietary frying oils. Am J Clin Nutr 78:1092-1097

19. Fernández-Real JM, Vayreda M, Richart $C$ et al (2001) Circulating interleukin 6 levels, blood pressure and insulin sensitivity in apparently healthy men and women. J Clin Endocrinol Metab $86: 1154-1159$ 
20. DeFronzo RA, Tobin JD, Andres R (1979) Glucose clamp technique: a method for quantifying insulin secretion and resistance. Am J Physiol 237:E214-E223

21. Dzienis-Straczkowska S, Straczkowski M, Szelachowska M, Stepien A, Kowalska I, Kinalska I (2003) Soluble tumor necrosis factor-alpha receptors in young obese subjects with normal and impaired glucose tolerance. Diabetes Care 26:875-880

22. Kilpatrick DC (2002) Mannan-binding lectin: clinical significance and applications. Biochim Biophys Acta 1572:401-413

23. Neth O, Hann I, Turner MW, Klein NJ (2001) Deficiency of mannose-binding lectin and burden of infection in children with malignancy: a prospective study. Lancet 358:614-618

24. Hansen TK, Thiel S, Wouters PJ, Christiansen JS, Van den Berghe G (2003) Intensive insulin therapy exerts antiinflammatory effects in critically ill patients and counteracts the adverse effect of low mannose-binding lectin levels. J Clin Endocrinol Metab 88:1082-1088

25. Fruebis J, Tsao TS, Javorschi S et al (2001) Proteolytic cleavage product of $30-\mathrm{kDa}$ adipocyte complement-related protein increases fatty acid oxidation in muscle and causes weight loss in mice. Proc Natl Acad Sci USA 98:2005-2010

26. Scherer PE, Williams S, Fogliano M, Baldini G, Lodish HF (1995) A novel serum protein similar to $\mathrm{C} 1 \mathrm{q}$, produced exclusively in adipocytes. J Biol Chem 270:26746-26749

27. Tenner AJ, Robinson SL, Ezekowitz RA (1995) Mannose binding protein (MBP) enhances mononuclear phagocyte function via a receptor that contains the $126,000 \mathrm{M}(\mathrm{r})$ component of the $\mathrm{C} 1 \mathrm{q}$ receptor. Immunity 3:485-493

28. Soell M, Lett E, Holveck F, Scholler M, Wachsmann D, Klein JP (1995) Activation of human monocytes by streptoccocal rhamnose glucose polymers is mediated by CD14 antigen, and mannan binding protein inhibits $\mathrm{TNF}-\alpha$ release. J Immunol 154:851-860

29. Bouwman LH, Eerligh P, Terpstra OT et al (2005) Elevated levels of mannose-binding lectin at clinical manifestation of type 1 diabetes in juveniles. Diabetes 54:3002-3006

30. Hovind P, Hansen TK, Tarnow L et al (2005) Mannose-binding lectin as a predictor of microalbuminuria in type 1 diabetes: an inception cohort study. Diabetes 54:1523-1527

31. Saraheimo M, Forsblom C, Hansen TK et al (2005) Increased levels of mannan-binding lectin in type 1 diabetic patients with incipient and overt nephropathy. Diabetologia 48:198-202

32. Hansen TK, Tarnow L, Thiel S et al (2004) Association between mannose-binding lectin and vascular complications in type 1 diabetes. Diabetes 53:1570-1576

33. Hansen TK, Thiel S, Knudsen ST et al (2003) Elevated levels of mannan-binding lectin in patients with type 1 diabetes. J Clin Endocrinol Metab 88:4857-4861

34. Garred P, Harboe M, Oettinger T, Koch C, Svejgaard A (1994) Dual role of mannan-binding protein in infections: another case of heterosis? Eur J Immunogenet 21:125-131

35. Walsh MC, Bourcier T, Takahashi K et al (2005) Mannosebinding lectin is a regulator of inflammation that accompanies myocardial ischemia and reperfusion injury. J Immunol 175:541-546

36. Fernandez-Real JM, Ricart W (1999) Insulin resistance and inflammation in an evolutionary perspective: the contribution of cytokine genotype/phenotype to thriftiness. Diabetologia 42:1367-1374

37. Mok MY, Jack DL, Lau CS et al (2004) Antibodies to mannose binding lectin in patients with systemic lupus erythematosus. Lupus 13:522-528 